\title{
ENTRE EL CONSERVADURISMO Y LA IDEALIZACIÓN ROMÁNTICA. LA ESPAÑA TRADICIONAL EN EL IMAGINARIO SOCIAL Y LITERARIO
}

\author{
BETWEEN CONSERVATISM AND ROMANTIC IDEALIZATION. \\ TRADITIONAL SPAIN BY THE SOCIAL AND LITERARY IMAGINARY
}

\author{
Francisco Entrena Durán \\ Universidad de Granada. España/Spain \\ fentrena@ugr.es
}

Recibido/Received: 09/06/2010

Aceptado/Accepted: 10/09/2010

\section{RESUMEN}

Tanto los viajeros románticos extranjeros, seducidos por el exotismo que veían en los escenarios espaciales y en las gentes de la España decimonónica que visitaron, como diversos pensadores y amplios sectores sociales de nuestro país, participaron de una común propensión a sobrevalorar el mundo tradicional y/o rural, la cual fluctuó entre el conservadurismo y la idealización más o menos costumbrista. Dicha sobrevaloración fue especialmente intensa con referencia a Andalucía, considerada entonces algo así como el paradigma idealizado de las esencias de lo español. En contraste con tales posiciones conservadoras e idealizadoras, se desarrollaron también actitudes y posiciones sociales o intelectuales más críticas, tales como la del movimiento anarquista campesino o la de los autores representantes del pensamiento social agrario hispano.

\section{PALABRAS CLAVE}

España Tradicional, imaginario social y literario, conservadurismo, idealización romántica.

\section{SUMARIO}

1. Introducción. 2. Entre el conservadurismo y la idealización romántica. 3. Las actitudes y posiciones más críticas del anarquismo rural y del pensamiento social agrario español. 4. Consideraciones finales: tres miradas ante la misma realidad social. Bibliografía.

\begin{abstract}
Both, romantic foreign travelers, who visited Spain in the nineteenth century seduced by the exoticism they found on its spatial settings and people, and important currents of thought and national social sectors, shared a common tendency to overestimate the traditional and / or rural world. Such tendency oscillated between conservatism and a certain idealization of typical local customs. This overestimation was expressed with particular intensity regarding Andalusia, which was viewed something like the idealized paradigm of the essences of being Spanish. In contrast to these conservative and / or idealizing positions, this same period shows us other more critical social or intellectual attitudes and positions, such as the peasant anarchist movement or different representative authors of what may be called as the Spanish agrarian social thought.
\end{abstract}

\section{KEYWORDS}

Traditional Spain, social and literary imaginary, conservatism, romantic idealization. 


\section{CONTENTS}

1. Introduction. 2. Between conservatism and romantic idealization. 3. More critical attitudes and positions by both rural anarchism and the Spanish agrarian social thought. 4. Concluding remarks: three standpoints on the same social reality. References.

\section{INTRODUCCIÓN}

Una de las principales razones de la dilatada permanencia de nuestro país en ese largo periodo histórico, de duración imprecisa y variable de unos contextos geográficos a otros y que se ha dado en conceptuar como el Antiguo Régimen, es el fracaso de lo que se conoce como la revolución industrial durante el siglo XIX (Nadal: 1977). Fracaso que está estrechamente relacionado con la circunstancia de que las tentativas modernizadoras de carácter centralizador, impulsadas por las actuaciones del Estado en el siglo XIX, carecieron de continuidad temporal y de apoyos sociopolíticos suficientes para afianzarse y cambiar las cosas. De esta forma, vacilante y versátil, la vida política española durante el siglo XIX se quedó en la superficie de la sociedad (Vilar: 1975, 85). La escasez y el mal estado de las comunicaciones, con el consiguiente aislamiento localista, son causas y efectos de la exigua penetración institucional del aparato estatal en el entramado social y territorial. Desde luego, los cambios modernizadores acometidos por los gobiernos liberales, materializados en gran medida mediante la desamortización o desvinculación de los patrimonios de la nobleza (y sobre todo de la Iglesia), modificaron profundamente las bases de la sociedad rural tradicional española decimonónica. Sin embargo, aunque seriamente afectada, esa sociedad mantuvo durante bastante tiempo la suficiente entidad como para ser capaz de generar una considerable capacidad de reacción. Una prueba de la tenaz persistencia de las estructuras socioeconómicas del Antiguo Régimen y de su considerable solidez y peso sociopolítico, lo constituye el hecho de que el Estado español del siglo XIX sólo disfrutó de un cierto nivel de estabilidad cuando contó con los sectores de la sociedad que, por ser beneficiarios de tales estructuras, estaban interesados en conservarlas. Eso ocurrió durante la Restauración monárquica (1875-1917), cuya relativa paz social es el producto de la coalición reaccionaria entre la entonces emergente y débil burguesía y la aristocracia terrateniente, que abogaba por el mantenimiento de unas estructuras agrarias de naturaleza oligárquico-caciquil (Costa: 1975 y Tussel: 1976).

En aquellas circunstancias, en las que había una clara preponderancia de la base social agraria, se explica que el foco de atención de los distintos actores sociales e intelectuales se centrara preferentemente en lo rural. Sin embargo, dado que los actores sociales y/o intelectuales ocupaban diferentes o contradictorias situaciones, también diferentes $\mathrm{o}$ contradictorias eran sus miradas y posiciones ideológicas con respecto a lo rural. De entre tales miradas y posiciones distinguimos a continuación entre el conservadurismo, el tipismo costumbrista e idealizador y las actitudes intelectuales y sociales más o menos críticas y/o reivindicativas. Una distinción que no pretende, ni mucho menos, llevar a cabo un tratamiento exhaustivo y sistemático de este asunto, sino que lo que básicamente se propone es mostrar que lo rural, y/o lo social en general, es el resultado de una construcción social (Entrena: 1998). Así, cuando hablamos de que lo rural se construye socialmente, no nos referimos sólo

a que dicha construcción varía temporal y espacialmente (es decir, según el momento 
histórico y de unos lugares a otros), sino también a que lo rural (muy especialmente, las posiciones y las percepciones acerca de ello) se ve modificado en razón de la perspectiva, los intereses o la posición social de los actores sociales que toman parte en su construcción social en un mismo tiempo y lugar, tal y como se pone de manifiesto en este trabajo.

\section{ENTRE EL CONSERVADURISMO Y LA IDEALIZACIÓN ROMÁNTICA}

En primer lugar, en lo que respecta al conservadurismo, el caciquismo, presente en la ideología y en las prácticas de los grupos sociales sustentadores del mismo en aquella época de nuestra historia, fue magistralmente descrito por Joaquín Costa cuando en 1902 publicó su conocida obra Oligarquía y caciquismo como la forma actual de gobierno en España (1975). Asimismo, Javier Tussel (1976) ha analizado la dominación caciquil de las oligarquías agrarias en Andalucía entre 1890 y 1923; es decir, el periodo histórico de máxima influencia de dicha dominación. Por ello, aquí sólo voy a referir como el conservadurismo no se limitaba a las prácticas y las actitudes ante la política, sino que también se extendía a la generalidad de la conciencia social y de los discursos de todos aquellos grupos, clases o individuos que, por una u otra razón, abogaban por la permanencia del orden del Antiguo Régimen.

Por ejemplo, en el plano de la literatura, Cecilia Böhl de Faber (1796-1877), más conocida como Fernán Caballero, el seudónimo con el que firmó sus libros, constituye uno de los más significativos representantes del conservadurismo social e ideológico. El recurso al clásico tópico de alabanza de la vida aldeana y el menosprecio de la urbana sirve de sostén argumental a la obra de Fernán Caballero, en la que esta autora justifica su idealización del mundo campesino tradicional porque considera que en él "están compendiadas todas las virtudes que corren peligro de desaparecer, desplazadas por la llegada de las modas y hábitos extranjerizantes" (González Troyano: 1996, 23). En consonancia con esto, la narrativa de Fernán Caballero, que se centra básicamente en la Andalucía rural tradicional, está anclada en una imagen de esta región "como un paraíso idílico en el que ciertas formas de vida eran aún posibles. Pero la conservación de ese mundo, con la armonía social y las virtudes con que ella lo contemplaba, estaba expuesta a perderse ante los peligros que para la tradición representaban el positivismo y la ofensiva de los ideales laicos y liberales del progreso. Fue la suya, por tanto, una perspectiva inmovilista, defensora a ultranza de una sociedad que ella viose obligada a idealizar en grado sumo: así el pueblo andaluz, sobre todo el vinculado con el campo, aparece en sus escritos, como el depositario de las mejores esencias y tradiciones, mientras que recaen sus condenas sobre aquellos otros que, según ella, encarnaban todos los vicios, los partidarios de actitudes agnósticas y democráticas, casi siempre enraizados en la vida pervertida de las ciudades" (González Troyano: 1996, 51). No es de extrañar pues que este ideario le granjeara, según nos cuenta el propio González Troyano, "numerosas amistades en la corte y en la nobleza andaluza y entre los literatos de talante más conservador” (1996, 53-54).

En esa misma línea, conservadora e idealizadora de lo rural y / o lo tradicional, se sitúan los viajeros románticos, para los que uno de los territorios preferidos es Andalucía, cuyo secular subdesarrollo deviene en exotismo ante sus ojos. Tales viajeros ven a Andalucía como "un país de romance a causa de su paisaje, clima, sacerdotes, bandidos, doncellas de ojos oscuros y danzas, que suman los numerosos arabic remanins, que en 
ninguna otra parte se encuentran mejor conservados ni alcanzan tan alto grado de perfección" (Krauel Heredia: 1986, 79). Todo ello, a su vez, explica que vieran España como 'el país de lo imprevisto', dentro del cual, sobre todo en Andalucía, el viaje se configuraba "desde un principio como una aventura más o menos azarosa, en la que, al mal estado de los caminos y las deficiencias de los albergues y posadas", se sumaba el fenómeno del "bandolerismo, this romantic feature of Spanish travelling en palabras de John Leycester Adolphus" (Krauel Heredia: 1986, 178 y 191; Soler Pascual: 2006; Cruz Casado: 2008). Y, dentro de Andalucía, Granada venía a ser una representación particularmente ajustada del pintoresquismo y los sueños de aventura anhelados por los románticos. Una actitud que no debería extrañarnos cuando tenemos en cuenta que, incluso en la propia literatura española, Granada constituía la encarnación morisca de numerosos romances y leyendas (Viñez Millet, 1982).

Los primeros viajeros románticos que recorrieron Andalucía encontraron un territorio firmemente anclado en el Antiguo Régimen. Sin embargo, a medida que avanzaba el siglo XIX España, y en particular Andalucía, experimentó transformaciones que conllevaron un gradual declive de las viejas estructuras e instituciones sociales. Ante estos cambios, los viajeros románticos, en general, tendieron a idealizar la vieja organización del mundo rural y la España tradicional, lo cual resulta más comprensible si se tiene en cuenta que, mediante sus viajes, aquellos románticos pretendían evadirse de los contextos de creciente modernización y racionalización de sus países de procedencia. Por ello, lo pintoresco y lo exótico, asociados al pasado tradicional por el que solían manifestar más o menos nostalgia, era lo que les interesaba, y no la tardía y lenta industrialización de España (Krauel Heredia: 1986 178, 314, 315).

Un caso paradigmático a este respecto es el de Moritz Willkomm, un viajero romántico que, tras una estancia en Andalucía, publicó en 1882 su libro Las sierras de Granada. Así, según Joaquín Bosque Maurel, "aunque acepta el hecho de que 'los ferrocarriles todo lo nivelan y la cada vez mayor concurrencia de turistas en Andalucía, acabarán con la poesía popular de los pasados tiempos en las grandes ciudades como Sevilla y Granada', Willkomm cree esperanzadamente que 'esa poesía y la originalidad consiguiente se conservarán intactas todavía en las pequeñas poblaciones andaluzas, especialmente en los valles de Sierra Nevada y en esa Alpujarra tan alejada de la comunicación general y del camino ordinario de los turistas"” $(1993,30)$.

Seducidos como estaban por los paisajes, los tipos originales y lo pintoresco de los países y los territorios que visitaban, se explica que la generalidad de los viajeros románticos estuviera menos interesada por conocer las leyes, las instituciones y el estado moral y social de tales territorios y países (Krauel Heredia: 1986, 33). Es más, cuando se referían a ese estado moral y social, lo hacían, a menudo, recurriendo a estereotipos que en nada resultaban apropiados para explicar las razones sociales estructurales subyacentes al mismo.

En este sentido, Blanca Krauel Heredia (1986, 252-253) refiere cómo los viajeros románticos, a su paso por la Baja Andalucía, clamaban por la indolencia, la pereza y otros defectos para ellos supuestamente congénitos del campesino andaluz. Esto, sobre todo, a su paso por Jerez de la Frontera, a pesar de que su conocimiento de la población rural de la zona se limitó a lo que habían oído contar en las tertulias de los notables jerezanos. En contraste, cuando viajan por las zonas abruptas de la Serranía de Ronda y observan lo 
trabajoso de la preparación para el cultivo de tierras muy pedregosas (en las que se tienen que hacer numerosos majanos) se sorprenden de una laboriosidad campesina que rompe su anterior tópico. Una contradicción que ellos explican esquemáticamente mediante la teoría del challenge and response que un siglo después popularizaría Arnold J. Toynbee, de acuerdo con la cual, si el suelo es ingrato, requiere mayor esfuerzo y laboriosidad, tal y como ocurre en el área rondeña. Por el contrario, en las llanuras suroccidentales de Andalucía, donde está ubicado Jerez, parece que basta con echar la semilla y esperar a que la tierra haga el resto.

En definitiva, se recurre a explicaciones sobre la supuesta indolencia o laboriosidad campesinas que no pueden ser más esquemáticas y simplistas, pues se ignora la repercusión crucial que en ello tienen las diferencias en la estructura de la propiedad: de carácter latifundista en el área de Jerez y con predominio del minifundismo en la Serranía de Ronda (Justicia Segovia: 1987; Rodríguez Martínez: 1977). Esto lleva a los pequeños propietarios de la Serranía a afanarse por obtener todo el rendimiento que pueden de su pequeña parcela, mientras que en la zona de Jerez la ociosidad o laboriosidad de los jornaleros no depende de ellos sino de los terratenientes, que deciden cuando y como emplearlos en función de sus necesidades estacionales de mano de obra o de los criterios más o menos intensivos con los que explotan sus fincas.

Dentro de la misma tendencia a caer en los estereotipos y en las simplificaciones, otros viajeros atribuyen la situación social andaluza al clima de la región. Tal es el caso de Henry David Inglis, quien, según nos cuenta Blanca Krauel Heredia (1986, 325), considera que la abundancia de mendigos y de personas de aspecto desdichado en Sevilla, así como la pereza que a su juicio manifiestan los andaluces en general, son debidas al clima caluroso de la región. Un clima que, en su opinión, hace desaconsejable trabajar con brío, además de que resta incentivos a cualquier tipo de tareas. En suma, una explicación completamente acrítica con el orden establecido que deja de lado la verdadera razón de este problema social, que es fundamentalmente la existencia de altas cotas de miseria engendradas por una distribución de la propiedad agraria muy desigualitaria y una organización social a todas luces injusta.

A las mitificaciones, con respecto a la supuestamente gran riqueza agraria de Andalucía, y a los tópicos relativos a como ello era causa fundamental de la ociosidad de sus gentes, contribuyeron también los escritos de determinados autores españoles, como es el caso de Fermín Caballero. Éste, en su Memoria sobre el Fomento de la Población Rural, se refería casi idílicamente a la región en los siguientes términos:

"Por lo elevado de la temperatura, por lo bajo de la latitud y del nivel, por la feracidad del suelo, y demás favorables circunstancias, crecen allí el plátano, el algodonero, la caña de azúcar, limoneros, naranjos, bosques de palmitos, y de acebuches y otras varias plantas, que pasan por exóticas en la flora atlántica: y a tan felices condiciones, reconocidas por los antiguos y celebradas en los escritos, que colocaron por aquí el Edén y los elíseos campos, morada de los varones justos y bienaventurados, fue debido quizá que esta tierra privilegiada excitase la codicia de extranjeros dominadores, desde los fenicios hasta los árabes (...) La abundancia de varias producciones, y la influencia de un cielo hermoso, de luz vivificadora, han debido afectar naturalmente al carácter de los habitantes, que sin disputa tienen más 
imaginación que laboriosidad, más fantasía que aplicación, mayor tendencia a la poesía y oratoria que a las faenas duras: su mente se cierne de continuo en un horizonte encantador, y sus miembros languidecen con el ardor del sol, inclinándolos a la sensualidad y a la molicie. Así es que la producción agraria debe más a la pujanza del terreno, que al esmero en el cultivo (...) Descontad la bondad del clima, la riqueza vegetativa de las cuencas y llanuras, y el solo trabajo del hombre ofrecería bien poco que alabar" (Caballero: 1863, 42).

Si bien es innegable que en el grueso de la obra de Fermín Caballero preponderó siempre una actitud crítica y su pensamiento no puede ser tildado en absoluto de conservador, lo cierto es que el párrafo anterior nos presenta un marco ideal que refleja, no tanto una realidad objetiva como una "construcción o imagen mental" acerca de Andalucía y de su población. Con ello se ignora esa otra Andalucía semidesértica y seca, en la que no se dan en absoluto tan favorables circunstancias de fertilidad (Sánchez Jiménez: 1994, 15). Una construcción que tampoco tiene en cuenta el hecho de que, para entender el carácter de los pueblos, no habría que centrarse en buscar las motivaciones geográficas o físicas del mismo, no se debería dirigir la atención a tratar de encontrar cuáles son sus 'causas naturales'. Entre otras razones porque ello podría conducir a determinismos más o menos esencialistas y a conclusiones tan absurdas como que los habitantes de las zonas con climas y condiciones naturales prácticamente iguales -de las que hay muchas en el mundotendrían el mismo o muy similar carácter. Por consiguiente, dado que sería un disparate ignorar la evidente capacidad de las sociedades de sobreponerse a las condiciones geográfico-naturales de sus entornos, lo conveniente es aproximarse al carácter individual y colectivo de las gentes como algo que es socialmente construido. Una construcción en cuyos resultados tienen mucho que ver el contexto de oportunidades de desarrollo social y vital que ofrecen las estructuras sociales en las que la misma acontece. En definitiva, más que por las condiciones geográficas y naturales de la región (que, además, no eran en amplios territorios de Andalucía tan óptimas como se describían desde perspectivas tan idealistas como las mencionadas), habría que explicar la ociosidad de muchos de los habitantes de la región como una situación socialmente construida, como un estado de cosas al que se veían forzados por su carencia de propiedad y míseras condiciones de existencia, y, en general, por las escasas oportunidades de trabajo y de realización sociovital que les ofrecían las altamente desiguales estructuras de la propiedad de la tierra.

De todas formas, continuando con la idea de Andalucía que tenían diferentes autores y viajeros decimonónicos, es obligado reconocer que no todos ellos manifestaron puntos de vista tan simplificadores y faltos de sentido crítico. Un significativo ejemplo a este respecto es Townsend, quien rechazaba la idea del andaluz perezoso cuando describía los viñedos malagueños, situados en las laderas de los montes, en la cara solana de los mismos, y resaltaba el hecho de que nadie puede imaginarse lo duro que resulta el trabajo en semejante contexto. A su entender, los campesinos de ningún otro país de la tierra soportaban mejor el calor, el hambre y la sed, o eran capaces de mayores esfuerzos que aquellas gentes a las que otros acusaban de indolencia. Por ello, Townsend aseguraba que, según él mismo había observado y podido comprobar, si los españoles de las provincias interiores estaban desempleados, no era por motivo del clima, de su pereza o indolencia, 
sino por otras causas, entre las que mencionaba "la negligencia del gobierno" (Krauel Heredia: 1986, 326).

\section{La mitificación idealizadora de Andalucía por parte de los viajeros románticos}

En cualquier caso, la perspectiva de Townsend es minoritaria, pues lo habitual es que la mirada de los escritores y/o de los viajeros románticos sobre España (y muy especialmente sobre Andalucía) no fuera más allá de los meros estereotipos y de la búsqueda o el ensalzamiento de lo pintoresco. Aunque hay que reconocer que esto no siempre los llevaba a posiciones conservadoras ni les impedía mantener una actitud crítica, tal y como la que tuvo Fermín Caballero. En particular, en lo que respecta a los viajeros románticos, tampoco puede tildarse de conservadora la posición de todos ellos, pues su frecuente idealización de las costumbres tradicionales, los rasgos físicos, el carácter y los paisajes (en definitiva, la construcción de una imagen mítico-paradisíaca y sublimada del territorio que visitaban) respondía más bien a la necesidad de tales viajeros, procedentes de una Europa en aquel tiempo más desarrollada y modernizada, de satisfacer sus propias carencias y anhelos de tradición en la entonces subdesarrollada e inmersa en el pasado España y, muy especialmente, Andalucía. Esto se patentiza con bastante intensidad en los tres viajeros románticos franceses Théophile Gautier, Prosper Mérimée y François-René de Chateaubriand.

Tanto Chateaubriand como Mérimée y Gautier recorrieron prácticamente los mismos caminos y visitaron los mismos lugares. Sin embargo, cada uno de ellos percibió una Andalucía completamente diferente, siendo consiguientemente también diferente el modo como la reflejaron en sus respectivos escritos. En primer lugar, Chateaubriand, que había prestado una mínima atención al paisaje andaluz (la mayor parte de su recorrido a lo largo de unos 350 kilómetros por Andalucía lo hizo de noche), una vez que retornó a Francia, compensó esto documentándose ampliamente acerca de la 'Andalucía mágica' de la que se había zafado durante su estancia. Su imaginación de 'mago' situó su Dernier Abencerraje, verdadero poema en prosa, en Granada y su Alhambra, el santuario por antonomasia de la magia andaluza.

En cuanto a Mérimée, los estereotipos españoles de la literatura romántica francesa que había ido a buscar en España, y cuyo prototipo había hallado más de una vez en los caminos y en las ventas de Andalucía, se convirtieron en sus cuentos en arquetipos humanos dotados de unas dimensiones y una profundidad tales que trascienden su carácter exclusivamente andaluz. De esta forma, Mérimée logró algo que difícilmente se puede afirmar con referencia a otros escritores-viajeros por España. Lo mismo que ellos, fue a Andalucía buscando -y encontrando- a los prototipos de las imágenes que ya albergaba en su idea personal de una España estilizada, romantizada. Sin embargo, dada la especial fuerza de su escritura, consiguió "hacer estallar el estereotipo regionalista para ofrecer así a cada uno de nosotros -de todas las generaciones y en todos los países- un arquetipo tal vez español, pero también profundamente humano" (Hempel-Lipschutz: 1987, 89 y 95). Esto se patentiza muy especialmente en el personaje de su mundialmente conocida obra Carmen (publicada en 1845), cuyo drama amoroso se ha erigido en algo así como un paradigma universal de la mujer fatal y del hombre seducido por ella o, de acuerdo con otras interpretaciones, en un prototipo del destino trágico de una mujer, adelantada a su tiempo, 
empeñada en vivir su amor sin ataduras ni sumisiones a ningún varón (Ramón y Préneron: 2006; Powrie, Babington, Davies and Perriam: 2007; Suárez: 2007).

Finalmente, Gautier sentía una profunda unidad, o mejor dicho identidad, con una idea de Andalucía que llegó a transformar hasta su propia personalidad. Sostuvo siempre que se sentía en su fuero interno más mediterráneo, más español y hasta más árabe que francés del siglo XIX. En Andalucía Gautier se confundió con el medio ambiente, dejando de mirar el decorado desde fuera y penetrando en su interior, viviendo y 'viviéndose' dentro de él, volviéndose, de esta forma, más español en sus comportamientos que incluso los propios españoles. Ello se patentiza, por ejemplo, en el hecho de que se aficionó apasionadamente a los toros o, asimismo, cuando mandó que le hicieran y vistió un traje de majo con motivo de su viaje de Granada a Málaga para asistir a las fiestas taurinas celebradas en la inauguración de la plaza de toros de esta ciudad. También, se alojó en el mismísimo corazón de la Alhambra. Todo ello muestra que Gautier sintió una comunicación casi mística con España, en la que creyó encontrar la realidad del espejismo vislumbrado en sus sueños de un paraíso que creía inaccesible (Hempel-Lipschutz: 1987, 90, 91, 93, 99, 100).

Diez años más joven que los grandes románticos hispanófilos de la primera generación (Víctor Hugo nació en 1802, Mérimée en 1803), Gautier comenzó a escribir sobre España, tras su viaje a través de ella en 1840 (Gautier: 1998), cuando la pasión españolista de estos dos predecesores suyos había llegado a su cima. Así, ya en el año 1830-31 fueron publicadas Hernani de Víctor Hugo, la colección de poemas de los Contes d'Espagne et d'Italie de Alfred de Musset y las primeras Lettres d'Espagne de Mérimée. Gautier, por su parte, soñaba con la España prefigurada por estos predecesores, y nunca ya se pudo sustraer a su hechizo. Ninguno de los viajes que efectuó por España consiguió modificar la imagen romántica preconcebida de nuestro país que traía Gautier. Se trata del espejismo de una España literarizada, de un país soñado, que nunca perdería para él su atractivo.

Es particularmente en Andalucía donde Gautier descubre "la sublimación de su verdadera España, su admiración y su contento no conocen límites al haber encontrado en ésta su 'paraíso'. En efecto, Andalucía representará para él en lo sucesivo la esencia misma de su España ideal. Aquí encuentra el color local cuya ausencia tanto había deplorado en Madrid, como es también en esta tierra donde ve [...] los prototipos originales de todos los personajes con los que poblará su España imaginaria. Aquí tiene oportunidad de viajar por verdaderos senderos de montaña infestados de bandoleros y de presenciar las mejores corridas de toros del mundo; $y$, sobre todo, aquí encontrará finalmente la encarnación de esa española ideal, 'con sus largas pestañas negras' y 'sus ojos de terciopelo' con la cual soñaba desde sus veinte años sin haberla encontrado” (Hempel-Lipschutz: 1987, 92-93).

Gautier "se siente profundamente emocionado por la belleza particular del paisaje andaluz: sus colores, sus formas, y sobre todo por su luz. En efecto, tan pronto como atraviesa Despeñaperros, experimenta una especie de aturdimiento, de arrobo ante los espacios abiertos y luminosos de esta Andalucía tan soñada por él. Es por fin en este paisaje donde reconoce su 'paraíso' hecho realidad visual. En la luz, primera creación divina para el paraíso original, reconoce Gautier la esencia profunda de su paradis retrouvé que es Andalucía [...]. Ningún pintor ni poeta ha percibido ni evocado mejor que Gautier [...] los destellos elusivos y las vibraciones temblorosas de la viveza de esta luz 
argentina que todo lo baña y que, a su vez, emana de todo: de los pueblos - ¡blancos, desde luego!- de las montañas, las rocas, hasta de los guijarros y la arenilla de los caminos, del agua que corre en los valles y de la nieve que cubre las cumbres" (Hempel-Lipschutz: 1987, 95-96).

En estas amplias citas de Hempel-Lipschutz se manifiesta una imagen paradisíaca de Andalucía, la cual, desde luego, no puede ser atribuida sólo a los viajeros más estetas y orientalizantes, tales como Gautier, Barón de Davillier, A. Dumas, Mérimée, etc., sino que también es característica de los más pragmáticos y contenidos como es el caso de los ingleses Borrow y Ford (Díaz López: 2006, 78 y ss). Especialmente enfáticos a este respecto son los viajeros naturalistas: Chapman y Buck, Boissier, Willkomm. Pues bien, con relación al carácter edénico atribuido a Andalucía por todos estos autores viajeros, López Ontiveros señala:

"El edén se justifica no por los habitantes de la región, con los que en general se es muy crítico, sino por el sol, la luz, el clima, la fertilidad del suelo, el color, el exotismo africano, el arabismo, el pintoresquismo, el arte, su atraso mismo. En todo caso dicha imagen edénica se justifica, a su vez, en parte por el hecho de que 'África empieza en Despeñaperros'.

Evidentemente la extrapolación edénica a toda Andalucía por parte de los viajeros es una licencia geográfica inadmisible -aunque no todos la practican- que, en parte, se debe a la mayor concentración de visitas en los espacios andaluces más fértiles y de mejor clima: Valle y Bajo Guadalquivir y Costa Mediterránea. Y ello, a su vez, conlleva la preterición casi sistemática de las altas tierras orientales, ni fértiles ni templadas" (López Ontiveros: 2008, 29-31).

Por otra parte, si dirigimos nuestra mirada hacia los actores sociales autóctonos hispanos, vemos que el mundo rural tradicional fue, también, un referente fundamental para la patronal agraria y sus asociaciones (Rey Reguillo: 1992), así como para un importante fenómeno social de resistencia al cambio en el siglo XIX hispano como fue el carlismo (Rubio Y Talavera: 2008), cuya naturaleza preponderantemente campesina está en clara correspondencia con el hecho de que dicho fenómeno se desarrolló en una sociedad en su mayor parte agraria tradicional. Inmersos en el ámbito social de lo rural tradicional, los campesinos españoles que secundaron el carlismo se opusieron con gran intensidad a la modernización en defensa de su mundo. Pero, no se aferraban a lo rural contra cualquier tipo de progreso modernizador, sino que a lo que primordialmente se oponían era a una manera de concebir el progreso, por parte de los políticos y de los burócratas urbanos, que, además de influir en la desarticulación de su mundo, colisionaba frontalmente contra sus necesidades materiales y existenciales fundamentales.

El carlismo se extendió sobre todo por la franja norte de la península. Los sectores hegemónicos del Antiguo Régimen (el clero y la nobleza) encontraron en él una forma de articular su visceral oposición a los propósitos modernizadores de los liberales. La persistencia de las estructuras del Antiguo Régimen y su fuerte capacidad de reacción explica la considerable envergadura y la duración en el tiempo del carlismo, así como su habitual empecinamiento integrista y fanático en la defensa del mundo rural tradicional. 
En concreto, la emergencia y el desarrollo de las movilizaciones carlistas tuvieron lugar en el contexto de la fuerte resistencia colectiva generada frente a los cambios derivados de la desamortización y de la paulatina introducción de las relaciones capitalistas de mercado en el agro, lo que, a su vez, conllevó significativas transformaciones en las modalidades de posesión y de explotación de la tierra.

Los presupuestos del modelo de orden social y los principios doctrinales por los que se movilizó el carlismo constituían una tentativa de propiciar el mantenimiento y la legitimación de la, relativamente privilegiada, situación de la nobleza y de la Iglesia hispanas en la sociedad del Antiguo Régimen. En este sentido, el carlismo puede ser interpretado como una especie de propuesta de dicha sociedad contra el proyecto histórico liberal tendente a su eliminación (Aróstegui: 1985, 8). Sin embargo, faltarían a la verdad los que se empecinaran en presentar las guerras carlistas únicamente como la expresión de insurrecciones organizadas o manipuladas por los elementos más reaccionarios del clero que, en connivencia con las fuerzas sociales más 'tenebrosas' del antiguo orden nobiliario señorial, trataban de atraerse el apoyo de los campesinos en una lucha que sólo pretendía la preservación de su status quo. Como he mostrado en otro trabajo previo, el carlismo también constituye la manifestación de una clara rebelión del campesinado por el mantenimiento de sus condiciones vitales y socioeconómicas amenazadas a causa del progresivo afianzamiento del Estado moderno (Entrena: 1997). Desde este punto de vista, mediante el carlismo se materializa una reacción de los campesinos en contra de la modernización, que, lo mismo que la de la nobleza y el clero, no es exclusiva de nuestro país ni de aquella época. El visceral rechazo de lo moderno y el repliegue en una especie de construcción idealizada de la sociedad tradicional, característicos de los campesinos que combatieron en las filas carlistas, suelen ser rasgos comunes de distintos movimientos sociales típicos del campesinado tradicional de otros lugares. Por ejemplo, con fines meramente ilustrativos, se mencionan aquí los dos casos siguientes: el zapatismo, analizado en Entrena (1987), y el movimiento cristero mexicano, estudiado en Entrena (1986).

Al igual que sucedía en otros movimientos similares de resistencia al cambio modernizador, la acción colectiva de los carlistas tenía como referente legitimador de su horizonte de expectativas una especie de utopía regresiva que, a diferencia del proyecto de futuro característico de las revoluciones de las sociedades modernas, dirigía su mirada hacia un pasado rural mitificado e inexistente.

En general, tanto los autores anteriormente referidos como los sectores sociales (los nobles terratenientes, los clérigos y los campesinos aglutinados por el movimiento carlista) perciben la sociedad tradicional y/o rural como el escenario de unas tradiciones y de unas estructuras que idealizan más o menos y por las que suelen sentirse seducidos. De ahí, que, a menudo, lamenten su deterioro como consecuencia del progreso. $\mathrm{Y}$, he dicho perciben la sociedad tradicional y /o rural, ya que, tanto los viajeros y novelistas que muestran un pensamiento más o menos nostálgico del pasado o conservador (Fernán Caballero, Inglis, Willkomm...), como de los viajeros románticos (Chateaubriand, Mérimée, Gautier...), no hablan sólo de lo rural sino también de las ciudades, pero al fin y al cabo de ciudades inmersas en el orden tradicional del Antiguo Régimen. 


\section{LAS ACTITUDES Y POSICIONES MÁS CRÍTICAS DEL ANARQUISMO RURAL Y DEL PENSAMIENTO SOCIAL AGRARIO ESPAÑOL}

Estas actitudes y posiciones se desarrollaron en el contexto de larga persistencia de las estructuras sociales y mentales del Antiguo Régimen en España. En tales circunstancias, a diferencia de otros ámbitos europeos, en los que la industrialización y la paulatina modernización facilitaron el surgimiento y los primeros avances de la Sociología, en nuestro país la perpetuación de dichas estructuras llevó a que, más que un pensamiento propiamente sociológico, las condiciones existentes fueran más adecuadas para que se manifestara un especial interés por la situación socioeconómica del agro y del campesinado en los escritos de destacados representantes de lo que se conoce como el pensamiento social agrario. Tal es el caso, por referir algunos ejemplos, de autores tan significativos como Flórez Estrada, Juan Díaz del Moral, Joaquín Costa, Pascual Carrión o Severino Aznar, que han sido incluidos por Sevilla-Guzmán entre los precursores de la Sociología rural institucionalizada española (Newby y Sevilla-Guzmán: 1983, 176 y ss).

Una somera aproximación al pensamiento de tales precursores es suficiente para comprobar que todos ellos coinciden en considerar el mundo rural como el objeto central de sus desvelos personales e intelectuales (Sevilla-Guzmán, en Newby y Sevilla-Guzmán: 1983). Así, en la aportación de Flórez Estrada se muestra su rechazo al programa político del liberalismo burgués, a la vez que se manifiestan las deficiencias del programa ilustrado con referencia a los intereses del campesinado. También en el análisis de los conflictos jornaleros (tan persistentes secularmente en el agro español) que lleva a cabo Juan Díaz del Moral en su Historia de las agitaciones campesinas andaluzas (publicada en 1928) se evidencia un claro compromiso progresista de este autor con los intereses del campesinado, como progresista es también el populismo de Joaquín Costa. Éste, que evolucionó de un regeneracionismo conservador hacia posiciones cada vez más radicales, anhelaba un modelo de desarrollo rural y comunitario que posibilitara la permanencia de la población en el agro y la preservara de la proletarización (Ortí: 1975). Por otra parte, aunque sin duda menos crítico que los tres anteriores (sobre todo, en el último tramo de su vida en el contexto de la dictadura franquista), la preocupación central de Pascual Carrión por la problemática de los latifundios es otra muestra más del interés prioritario por lo rural del pensamiento social español.

Finalmente, la obra de Severino Aznar, constituye un ejemplo de como la preocupación por lo rural es una cuestión medular también en el pensamiento social más conservador. La aportación de este 'misionero social' se sustentaba en el catolicismo social reformista propugnado por León XIII en la Encíclica Rerum Novarum. Desde esta perspectiva, trataba de encarar el problema de las profundas desigualdades existentes en el agro mediante el fomento del acceso a la propiedad de los asalariados y a través de la creación de una clase de medianos propietarios, que garantizaría la estabilidad social frente a la posibilidad de cualquier amenaza revolucionaria (Newby y Sevilla-Guzmán: 1983, 201).

En suma, independientemente de sus propósitos conscientes y de que sus particulares planteamientos sean más o menos conservadores o progresistas, las obras de los autores referidos manifiestan distintos grados de compromiso intelectual y de preocupación por los problemas socioeconómicos de la sociedad rural; en gran parte, 
motivados por el gradual proceso de modernización experimentado por España desde el siglo XIX. Pero, mientras que desde el punto de vista del pensamiento sociológico europeo de entonces, predominantemente inserto en los paradigmas teórico-culturales de la modernidad, lo rural solía constituir un referente del atraso a rechazar o superar, para los mencionados representantes del pensamiento social español, lo rural era su objeto central de estudio, como ámbito en el que se generaban y a partir del que era posible explicar o solventar los problemas fundamentales existentes en el país.

Al igual que los autores que acabo de referir, el movimiento anarquista, tan fuertemente implantado en la Andalucía de entonces (Maurice: 2007), manifestó también unas preocupaciones y una visión marcadamente ruralistas de los problemas existentes, de tal forma que los horizontes de expectativas y los referentes de identificación del ideal de orden socialista añorado por los anarquistas campesinos se ubicaban claramente en el ámbito existencial y cultural del mundo rural de su tiempo. La frecuente visión localista de los problemas y el fuerte rechazo del Estado, por parte de muchos de los que secundaron las movilizaciones anarquistas, se explica por la usual tendencia de los campesinos tradicionales, dado su secular aislamiento y autárquico modo de vida, a entender el mundo desde los marcos localistas inmediatos en los que se desenvolvía su cotidianeidad. De todos modos, hay que aclarar a este respecto que hablamos del comportamiento del grueso del campesinado anarquista y no de sus líderes. Éstos, como acertadamente puntualizaba Juan Díaz del Moral, mostraban una percepción más compleja de la situación en la que se desenvolvían y de los objetivos por los que luchaban que los simples militantes de base $(1979,199)$.

Además, para entender el rechazo anarquista del Estado, hay que tener en cuenta que una gran parte de la sociedad rural andaluza de aquel tiempo, lejos de encontrar en la autoridad estatal un agente encaminado a solventar sus problemas o a mejorar sus penosas condiciones de vida, hubo de soportar un alto grado de corrupción y de opresión por parte de esa autoridad, lo que repercutió notablemente en la desarticulación de su mundo. En tan penosa situación, el Estado era percibido por muchos campesinos como una instancia que atentaba contra la, a su entender, ancestral naturaleza comunitaria de la sociedad agraria, como el causante de la desvirtuación de ésta en tanto que soporte político-institucional de una estructura de distribución de la tierra profundamente inequitativa e injusta.

Por otra parte, en el contexto de profunda crisis estructural en el que entonces se encontraba la sociedad rural tradicional hispana, se experimentó una fuerte propensión colectiva a buscar lo 'milagroso' o lo mágico y/o extraordinario, como forma de obtener aquellas compensaciones o respuestas materiales y psíquicas que el orden social no proporcionaba. Pero, el hecho de que las inclinaciones hacia la búsqueda de lo 'milagroso' estuvieran muy extendidas entre la población sólo evidencia una actitud de ésta ante su carencia de medios instrumentales para enfrentarse al entorno, pues ello no implica que existiera un alto el grado de interiorización popular de la religión, el cual, por contra, era apreciablemente bajo. La conciencia religiosa conlleva la internalización de una racionalidad moral sagrada y supramundana que propugna una serie de medios para conseguir determinados fines. Frente a este sentido de la religión, que Weber (1979) denominó racional-ético, para la espiritualidad popular española de entonces, lo sagrado, en vez de una referencia moral o un consuelo de un 'más allá' que compensara el sufrimiento de esta vida, solía ser percibido como algo a lo que se recurría en demanda de solución de ciertos 
problemas particulares o para satisfacer determinados intereses personales. Se trataba, en definitiva, de una sociedad rural tradicional cerrada y localista, cuyos referentes culturales estaban regidos por lo mágico y la superstición y en la que, por lo tanto, era habitual el adorno con mantos y joyas de las supuestas imágenes de vírgenes rupestres que la población creía identificar en las formas de las rocas de las sierras, o bien de las imágenes famosas de las ciudades. Una sociedad, en la que también era corriente el uso de escapularios y de medallas para protegerse de maleficios o, incluso, el encender velas a los santos, por parte de los numerosos proscritos y bandoleros entonces existentes, con el fin de asegurarse el éxito en sus tareas al margen de la legalidad (Quirós y Ardila: 1978, 237). Como una muestra más del ambiente de oscurantismo y superchería existente en aquel contexto, estos mismos autores nos relatan un caso que contribuye a mostrar el considerable arraigo de la superstición en aquella época. Según refieren, en cierta ocasión, un grupo de malhechores se aproximaba a un pueblo a cometer un delito y se les cruzó una zorra en el camino. 'Zorra a principio de cazadero es siempre de mal agüero', observó uno de ellos. Y todos convinieron en aplazar su acción para otro día, a la espera de un buen augurio (Quirós y Ardila: 1978, 238).

\section{CONSIDERACIONES FINALES: TRES MIRADAS ANTE LA MISMA REALIDAD SOCIAL}

A lo largo del sigo XIX España experimentó un paulatino declive de las viejas estructuras e instituciones sociales. Sin embargo, los cambios producidos fueron de tan escasa magnitud que puede afirmarse que, incluso durante la primera mitad del siglo XX, el país permaneció anclado en el Antiguo Régimen; es decir, siguió siendo una sociedad básicamente agraria fragmentada en diversos particularismos regionales más o menos cerrados, autárquicos y localistas. Como se ha mostrado en las páginas precedentes, esta situación fue vista o encarada de manera diferente según los distintos actores sociales concernidos de una u otra forma con ella. Así, de la misma forma que ciertos escritores y viajeros románticos manifestaron sus puntos de vista nostálgicos, conservadores o idealizadores de la realidad social del mundo rural y/o tradicional español (y especialmente del andaluz), hubo otros actores sociales y escritores que afrontaron esa misma realidad desde posiciones mejor fundamentadas analítica y científicamente, a la vez que más críticas. Por lo tanto, tenemos tres miradas ante una misma realidad social: la conservadora, la idealizadora y la crítica. Cada una de dichas miradas proviene de una tipología de actores sociales distinta que ocupaban unas posiciones socioeconómicas diferentes, las cuales pueden ser esquematizadas de la forma que sigue:

- La posición conservadora de aquellos intelectuales y sectores tradicionales, más o menos afines a la nobleza, al clero y a otras clases sociales, que, de una u otra forma, tenían interés en preservar el Antiguo Régimen.

- La posición idealizadora de los viajeros románticos, cuya pretensión básica no era tanto mantener intactas las viejas estructuras (es decir, lo que sería calificable como un conservadurismo social) como salvaguardar unos paisajes, unos estilos de vida y unos caracteres sociales por los que se sentían profundamente atraídos, en tanto que los 
consideraban como prototipos ideales de la identidad de lo español. Como consecuencia de ello, dichos viajeros tendieron a identificar su España soñada/prefigurada con la España real, contribuyendo así a la construcción, difusión, universalización, perpetuación de los estereotipos y clichés que elaboraron con respecto al carácter colectivo de nuestro país.

- La posición de aquellos sectores sociales e intelectuales preocupados por las injusticias y por las profundas desigualdades existentes en el mundo rural tradicional español (muy especialmente, en el andaluz) y, por lo tanto, comprometidos con su cambio. En este sentido, en contraste con los relatos idealizados y los estereotipos acerca de lo rural tradicional antes referidos, se desarrolló un pensamiento social crítico, que trataba de aproximarse a la realidad social mediante enfoques analíticos científicamente más rigurosos, los cuales, desde luego, no pueden ser calificados como sociológicos, sino como precursores de la Sociología, ya que aún no estaban dadas las condiciones socioeconómicas adecuadas para propiciar el desarrollo de dicha ciencia social en nuestro país.

En este contexto se explica que el mundo rural tradicional, en tanto que entonces predominante en España, constituyera un objeto de atención prioritaria en el imaginario de distintos representantes de la literatura nacional y extranjera y del pensamiento social, a la vez que un referente de identificación, tanto para las clases terratenientes y otros sectores sociales interesados en conservar su status quo, como para esa considerable parte del campesinado tradicional que se vinculó o identificó con el carlismo o con el anarquismo. En tales circunstancias, la dilatada persistencia del Antiguo Régimen fue, en gran parte, debida al peso determinante de las oligarquías agrarias tradicionales en la vida sociopolítica española, a que, en consecuencia, no prosperaron los diferentes intentos, proyectos y disposiciones legislativas tendentes a propiciar la modernización, así como a los prácticamente nulos efectos de las políticas modernizadoras acometidas en el inestable y breve intervalo de la Segunda República (14-04-1931 al 18-07-1936). Y, en gran medida, esto último fue una causa de las fuertes presiones que ejerció la minoría social terrateniente entonces hegemónica, que se opuso férreamente a los vacilantes intentos del gobierno republicano de transformar las estructuras socioeconómicas (López: 1984). Una minoría social que luego constituyó un sostén fundamental del franquismo y que, por lo tanto, fue la causante de que España persistiera anclada en el orden tradicional del Antiguo Régimen durante varias décadas más hasta que, a partir de los años cincuenta del siglo XX, la realineación del gobierno franquista junto a las potencias triunfantes en la Segunda Guerra Mundial (especialmente, con los Estados Unidos que, a cambio, instalaron bases militares en suelo español) llevó a una paulatina modernización de las estructuras sociales y culturales del país; sobre todo, de determinadas zonas del mismo como Cataluña, el País Vasco o Madrid.

\section{BIBLIOGRAFÍA}

ARÓSTEGUI, J. (1985): “Los Carlistas” en Aróstegui, J.; Blinkhorn, M.; Torre, J. M. y Fernández, M., Cuadernos de Historia 16, nº 280. 
BOSQUE MAUREL, J. (1993): "Un científico germano en Andalucía”. Estudio preliminar del libro de Willkomm, M. (publicado originariamente en 1882) Las sierras de Granada, Granada, Caja General de Ahorros y Monte de Piedad de Granada, Granada.

CABALLERO, F. (1863): Memoria sobre el fomento de la población rural, Madrid, Real Academia de Ciencias Morales y Políticas.

COSTA, J. (1975): Oligarquía y caciquismo como la forma actual de gobierno en España: urgencia y modo de cambiarla, Madrid, Ediciones de la Revista de Trabajo.

CRUZ CASADO, A. (2008): "El espejo infiel: una aproximación al bandolero romántico y su reflejo en la literatura española", Iberoamericana, $\mathrm{n}^{\circ} 31$.

DÍAZ DEL MORAL, J. (1979): Historia de las agitaciones campesinas andaluzas, Madrid, Alianza Editorial.

DÍAZ LÓPEZ, J. A. (2006): "Imagen de Andalucía en los viajeros ingleses del siglo XIX” en Egea Montesinos, A. (coord.) Dos siglos de imagen en Andalucia, Sevilla, Fundación Centro de Estudios Andaluces.

ENTRENA DURÁN, F. (1986): "Los levantamientos cristeros en México: entre la 'guerra santa' y la reivindicación agrarista", Revista de Indias, $\mathrm{n}^{\circ}$ 178, Madrid, Consejo Superior de Investigaciones Científicas.

- (1987): "El papel del campesinado en la Revolución mexicana", Cuadernos de Ciencia Política y Sociología, $\mathrm{n}^{\circ}$ 19, Madrid, Colegio Nacional de Doctores y Licenciados en CC. Políticas y Sociología.

- (1997): "La protesta campesina contra el Estado en la España tradicional", Revista de Sociología e Política, no 8, Brasil, Ed. Grupo de Estudos Estado e Sociedade (GEES), Departamento de Ciências Sociais da Universidade Federal do Paraná.

- (1998): Cambios en la construcción social de lo rural. De la autarquía a la globalización, Madrid, Tecnos.

GAUTIER, TH. (1998): Viaje a España, Madrid, Cátedra.

GONZÁleZ TROYANO, A. [et al.] (1996) Fernán Caballero. De la Andalucía romántica a la novela moderna, Cádiz, Ayuntamiento del Puerto de Santa María.

HEMPEL-LIPSCHUTZ, I. (1987): "Andalucía, de lo vivido a lo escrito, por tres románticos franceses: François-René de Chateaubriand, Prosper Mérimée y Théophile Gautier”, en La imagen de Andalucía en los viajeros románticos y Homenaje a Gerald Brenan, Málaga, Diputación Provincial de Málaga.

JUSTICIA SEGOVIA, A. (1987): "La estructura de la propiedad como elemento configurador del paisaje agrario. Ensayo metodológico aplicado a la comarca de La Axarquía (Málaga)", Anales de Geografía de la Universidad Complutense, $\mathrm{n}^{\circ}$ 7, Madrid, Universidad Complutense.

KRAUEL HEREDIA, B. (1986): Viajeros británicos en Andalucia: de Christopher Hervey a Richard Ford: (1760-1845), Málaga, Universidad de Málaga.

LÓPEZ LÓPEZ, A. (1984): El boicot de la derecha a las reformas de la Segunda República. La minoría agraria, el rechazo constitucional y la cuestión de la tierra, Madrid, Ministerio de Agricultura, Pesca y Alimentación, Serie Estudios.

LÓPEZ ONTIVEROS, A. (2008): La imagen de Andalucía según los viajeros ilustrados y románticos, Granada, Caja Granada, Obra Social, Cuadernos del Museo

MAURICE, J. (2007): El anarquismo andaluz, una vez más, Granada, Universidad de Granada, NADAL, J. (1977): El fracaso de la Revolución industrial en España, 1814-1913, Barcelona, Ariel. NEWBY, H. y SEVILLA-GUZMÁN, E. (1983): Introducción a la sociología rural, Madrid, Alianza Universidad.

ORTÍ, A. (1975): "Estudio Introductorio" en Costa, J. Oligarquía y caciquismo como la forma actual de gobierno en España: Urgencia y modo de cambiarla, Madrid, Ediciones de la Revista de Trabajo. 
POWRIE, PH.; BRUCE BABINGTON, A.D. y PERRIAM, CH. (2007): Carmen on Film: A cultural history, IN, Indiana University Press, Bloomington and Indianapolis.

QUIRÓS, C. B. DE y ARDILA, L. (1978): El Bandolerismo Andaluz, Madrid, Ediciones Turner.

RAMÓN TRIVES, F. y PRÉNERON VINCHE, P. (2006): Un mito español en la Literatura francesa : la Carmen de Mérimée, Alicante, Publicaciones de la Universidad de Alicante.

REY REGUILlO, F. DEL (1992): Propietarios y Patronos. La política de las organizaciones económicas en la España de la Restauración (1914-1923), Madrid, Ministerio de Trabajo y Seguridad Social.

RODRÍGUEZ MARTÍNEZ, F. (1977): La Serranía de Ronda. Estudio Geográfico, Málaga, Confederación Española de Cajas de Ahorros.

RUBIO LINIERS, M. C. y TALAVERA DÍAZ, M. (2008): El Carlismo, Madrid, Consejo Superior de Investigaciones Científicas.

SÁNCHEZ JIMÉNEZ, J. (1994): "Pequeña y gran propiedad a finales del siglo XIX: Andalucía", Cuadernos de Historia Contemporánea, $\mathrm{n}^{\circ}$. 16, Madrid, Universidad Complutense, Madrid.

SOLER PASCUAL, E. (2006): Bandoleros: mito y realidad en el romanticismo español, Madrid, Síntesis.

SUÁREZ SÁNCHEZ, E. (2007): "Don Juan y Carmen de Mérimée: un reto de miradas", Logosphère. Revista de Estudios Lingüísticos y Literarios, $\mathrm{n}^{\circ} 3$, Granada, Universidad de Granada.

TUSSEL, J. (1976): Oligarquía y caciquismo en Andalucía (1890-1923), Barcelona, Planeta.

VILAR, P. (1975): Historia de España, París, Librairie Espagnole.

VIÑEZ MILLET, C. (1982): Granada en los libros de viaje, Granada, Biblioteca de Escritores y Temas Granadinos, 8, Miguel Sánchez.

WEBER, M. (1979): Economía y Sociedad, México, Fondo de Cultura Económica.

\section{NOTAS:}

1 El presente texto ha sido seleccionado de entre los presentados al XV Congreso Nacional de Sociología en Castilla-La Mancha que, organizado por la Asociación Castellano-Manchega de Sociología, se celebrará en Almagro (Ciudad Real), los días 22, 23 y 24 de octubre de 2010.

\section{Breve currículo:}

\section{Francisco Entrena Durán}

Catedrático de Sociología de la Universidad de Granada (España), ha dirigido diversas tesis doctorales y formado parte de equipos investigadores nacionales e internacionales. Es autor de más de un centenar publicaciones, la mayoría de ellas en editoriales y revistas científicas españolas y extranjeras de amplia difusión nacional e internacional. Sus principales líneas de investigación son América Latina, Sociología Rural, Teoría Sociológica y Sociología de la Globalización. Entre sus publicaciones están: Cambios en la Construcción Social de lo Rural (Madrid, 1998) Modernidad y Cambio Social (Madrid, 2001), Local reactions to globalisation processes: competitive adaptation or socio-economic erosion (Nueva York, 2003), Diversificación de las desigualdades y estabilización social en Andalucía (Granada, 2006), y "Understanding Social Structure in the Context of Global Uncertainties", Critical Sociology, Julio 2009 vol. $35 \mathrm{~N}^{\circ} 4: 521-540$. 